\title{
Fundamentos e Microfundamentos da Capacidade Dinâmica da Firma*
}

\author{
Victor Pelaez \\ Universidade Federal do Paraná \\ Marcelo Melo \\ TECPAR \\ Ruth Hofmann \\ TECPAR \\ Dayani Aquino \\ TECPAR
}

\section{RESUMO}

O reconhecimento da firma como conjunto de recursos produtivos passíveis de serem recombinados tem sido, em uma perspectiva evolucionária, importante referência para o entendimento dos fenômenos de crescimento e competitividade empresarial. Nessa abordagem, a competitividade da firma é considerada resultado da sua capacidade de se adaptar a um ambiente incerto e cambiante. O reconhecimento desse ambiente baseia-se, por sua vez, na subjetividade da imagem que se forma na mente do empresário acerca das possibilidades e dos obstáculos de crescimento do negócio. É baseado nessa imagem, ou na sua capacidade de interpretação do ambiente, que o empresário toma decisões no sentido de coordenar os recursos capazes de concretizar as suas expectativas. $\mathrm{O}$ objetivo deste trabalho é discutir a interpretação e a coordenação como atividades econômicas intrinsecamente relacionais, nas quais a intersubjetividade atua como fator limitante e potencializador da racionalidade dos agentes.

\footnotetext{
* Agradecemos as contribuições críticas dos pareceristas que nos ajudaram a elucidar alguns aspectos importantes dos fundamentos teóricos discutidos no texto
} 
Palavras-Chave | Capacidade Dinâmica; Intersubjetividade; Coordenação; Interpretação; Decisão

Códigos JEL | B52; O33

\begin{abstract}
Following an evolutionary approach, the recognition of the firm as a set of recombinable productive resources has been an important reference for understanding their growth and competitiveness. This approach takes into account the firms competitiveness as a result of its capability to adapt to a changing and uncertain environment. The recognition of such an environment is based, in turn, on the subjective image built in the mind of the entrepreneur regarding possibilities for and obstacles to the companys growth. Based on this image, or on their capacity to interpret the environment, entrepreneurs take decisions aimed at coordinating resources in such a way as to achieve their expectations. The aim of this paper is to discuss interpretation and coordination as intrinsically relational economic activities, in which intersubjectivity can both limit and potentialize the rationality of agents.
\end{abstract}

KEYWORDS I Dynamic Capabilities; Intersubjectivity; Coordination; Interpretation; Decision

JEL-CODES | B52; O33 


\section{Introdução}

O reconhecimento da firma como um conjunto de recursos produtivos passíveis de serem recombinados tem sido, em uma perspectiva evolucionária, uma importante referência para o entendimento dos fenômenos de crescimento e de competitividade empresarial. Longe de uma condição objetiva de equilíbrio pré-determinada, o ambiente da firma é assimilado como um contexto incerto, fragmentado e em constante transformação. Nesse contexto, a competitividade da firma é considerada uma função das capacidades de integração e de reconfiguração de seus recursos no sentido de se adaptar às mudanças do ambiente. E o reconhecimento desse ambiente baseia-se não mais numa condição objetiva de equilíbrio, mas na subjetividade da imagem que se forma na mente do empresário das possibilidades e dos obstáculos de crescimento do negócio. É baseado nessa imagem, ou na sua capacidade de percepção/interpretação ${ }^{1}$ do ambiente, que o empresário toma decisões de investir no sentido de mobilizar/coordenar os recursos capazes de concretizar as suas expectativas de crescimento.

Tanto a interpretação quanto a coordenação são atividades intrinsecamente relacionais que dependem da existência e da interação com o Outro, reconhecendo-se assim a importância da intersubjetividade como fator limitante e potencializador de comunicação entre os agentes econômicos. Surge daí um problema de ordem ontológica no qual a racionalidade dos agentes no processo de tomada de decisão não se estabelece ex ante, mas durante um processo de interação que estabelece a rede de relações na qual ele se insere, ou seja, da intersubjetividade representada pela sua participação como elemento integrante de um sistema social. O objetivo dessa comunicação é de propor uma discussão teórico-metodológica da abordagem evolucionária das capacidades da firma, notadamente da análise da "capacidade dinâmica" proposta por Teece, Pisano e Shuen (2002).

A seção 2 do texto apresenta os elementos de análise dos referidos autores, levando em consideração as interações que se estabelecem entre as estratégias competitivas e organizacionais da firma. A seção 3 resgata dois

\footnotetext{
A intenção da segmentação dos termos é enfatizar os aspectos semânticos pertinentes à discussão, particularmente os aspectos relacionais.
} 
fundamentos teóricos que consideramos as principais fontes de referência desse tipo de análise: a teoria da firma proposta por Edith Penrose; e a abordagem evolucionária de Richard Nelson e Sidney Winter, no que tange à discussão da fonte da diversidade empresarial. Nesse nível de análise, ressalta-se a importância da combinação de elementos objetivos e subjetivos que contribuem para a compreensão do processo de tomada de decisão dos agentes ao utilizarem e desenvolverem as capacidades organizacionais da firma. E a seção 4 discute os microfundamentos teóricos voltados a uma abordagem cognitiva da mente do indivíduo - sob a ótica de comportamento do homem-econômico - cuja percepção incorpora elementos subjetivos e intersubjetivos de análise. A intersubjetividade dos agentes é discutida em três níveis de análise: o da interpretação do ambiente da firma que envolve um problema de interação entre os sistemas de percepção (individuais) e as redes de relações (coletivas); o da coordenação de recursos produtivos que envolve um problema de gestão de diferentes conhecimentos resultantes da divisão do trabalho no nível interno e externo da firma; e o da observação do pesquisador sobre o seu objeto de estudo (a firma), cuja organização prévia da experiência (teoria) tende a distorcer a interpretação dos resultados e a influenciar na própria interpretação dos agentes econômicos. É nesse terceiro nível de subjetividade que se discute a capacidade de se avaliar as capacidades da firma e de se reconhecer que a ciência econômica e a economia não representam uma dicotomia entre o teórico e o empírico, mas atividades que integram um coletivo heterogêneo e interdependente.

\section{Os elementos de análise}

A constatação de que o acúmulo de ativos tecnológicos não é suficiente para garantir vantagens competitivas advém da importância atribuída à capacidade que a firma possui de coordenar competências internas e externas de forma a adaptar-se a um ambiente em rápida transformação. É dentro dessa perspectiva que Teece, Pisano e Shuen (2002:339)² adotaram o termo "capacidade dinâmica" da firma no sentido da

\footnotetext{
2 O conteúdo desse artigo foi publicado originalmente em 1994 por David Teece e Gary Pisano e reeditado em dois artigos posteriores, com a participação de Amy Shuen, em 1997 e em 2002, como indicado nas Referências bibliográficas. Nesta comunicação adotaremos, sobretudo, a referência da versão de 2002, na qual os autores apresentam de forma mais sistemática os elementos de análise da capacidade dinâmica da firma.
} 
"ability to reconfigure, redirect, transform, and apropriately shape and integrate existing core competences with external resources and strategic and complementary assets to meet the challenges of a time-pressured, rapidly changing Schumpeterian world of competition and imitation".

Core competences é justamente o que diferencia uma firma de seus competidores, ou seja, a fonte da diversidade organizacional das empresas. Essa especificidade reduz as possibilidades de replicação das competências de uma empresa por seus concorrentes.

Dito de outra forma:

"The capabilities approach places emphasis on the internal processes that a firm utilizes, as well as how they are deployed and how they will evolve. The approach has the benefit of indicating that competitive advantage is not just a function of how one plays the game; it is also a function of the 'assets' one has to play with, and how these assets can be deployed and redeployed in a changing market". (2002:355)

Em uma perspectiva schumpeteriana, a vantagem competitiva seria determinada fundamentalmente pela capacidade inovativa da firma, a qual é continuamente desafiada pelo dinamismo tecnológico de seus concorrentes. E essa capacidade depende tanto do conhecimento científico-tecnológico que a firma possui, quanto da sua capacidade de coordenar seus recursos produtivos por meio da estrutura organizacional da firma. Como observam os referidos autores, o adjetivo "dinâmica" refere-se às mudanças detectadas no ambiente da firma, as quais provocariam mudanças internas, tanto no nível da organização quanto da tecnologia, fazendo com que o tempo se torne uma variável crítica, especialmente quando o ritmo de inovação se acelera e a natureza da concorrência é difícil de determinar (2002:337).

Essa interdependência entre a organização e o meio no qual ela se insere remete ao próprio conceito de estratégia que começou a ser desenvolvido a partir dos anos 60 nos EUA, notadamente com os trabalhos de Chandler (1962) e de Learned, Christensen, Andrews e Gut (1965) (Nicolau, 2001). Montgomery e Porter (1998:XII), ao citarem os trabalhos desses últimos autores, resgatam a discussão da estratégia como uma noção 
"[...] de adequação entre as capacidades únicas de uma empresa e as exigências competitivas de um setor que a distinguia das demais. $O$ desafio enfrentado pela gerência consistia em escolher ou criar um contexto ambiental no qual as competências e recursos característicos da empresa poderiam produzir uma vantagem competitiva. Essa estratégia seria então atualizada mediante um esforço consistente de coordenação das metas, políticas e planos funcionais da empresa".

A estratégia estaria assim associada à obtenção de vantagens competitivas por meio de um contínuo reposicionamento da empresa em relação aos seus competidores. Nessa perspectiva, Bruce Henderson, num artigo originalmente publicado na Harvard Business Review, em 1989, define estratégia como

"[...] a busca deliberada de um plano de ação para desenvolver e ajustar a vantagem competitiva de uma empresa. Para qualquer empresa, a busca é um processo interativo que começa com o reconhecimento de quem somos e do que temos nesse momento. [...] As diferenças entre você e seus competidores são a base da sua vantagem". (1998)

Em uma perspectiva evolucionista, na qual o ambiente de seleção do mercado é caracterizado pela variabilidade das respostas organizacionais das empresas, Teece, Pisano e Shuen (2002) se propõem a entender como as organizações desenvolvem capacidades específicas, a fim de se manter competitivas, e como tais capacidades são renovadas, a fim de responder às mudanças do ambiente.

Para responder a essas questões, os autores propõem um referencial de análise que conta com três elementos explicativos da vantagem competitiva obtida pela firma: a posição, os caminhos e os processos organizacionais.

A posição de uma empresa, em determinado momento de sua história, seria definida por seus ativos tecnológicos, ou seja, pelo seu know-how de produção; seus ativos complementares em atividades como a compra, a distribuição, a comercialização e os serviços de assistência técnica de seus produtos; seus ativos financeiros; e seus ativos locacionais. A posição define o núcleo de competências ou o eixo de negócios no qual a firma atua, caracterizado por 
meio de seus produtos e serviços, definindo ao mesmo tempo as suas relações externas com os clientes e os fornecedores (2002:341). Consideramos ainda que a participação relativa da firma, no mercado ou nos segmentos de mercado em que atua, é um elemento importante para definir a sua posição relativa vis-à-vis seus concorrentes.

O caminho, ou trajetória, seguido pela empresa é uma função das decisões tomadas no passado a partir das oportunidades produtivas identificadas. Existe aqui um duplo sentido, pois as oportunidades vislumbradas sugerem, por um lado, uma liberdade de escolha entre diferentes opções possíveis. Por outro, uma determinada escolha implica seguir determinada trajetória de investimento cujos custos tendem a ser irrecuperáveis, gerando uma condição de irreversibilidade (path-dependence). As decisões tomadas ao longo do caminho trilhado pela empresa dependem dos mecanismos de busca e avaliação das oportunidades produtivas a serem exploradas pela empresa, por meio dos quais se estabelecem os processos de aprendizagem e de acúmulo de conhecimento.

Os processos organizacionais remetem, por sua vez, à identificação e à solução dos problemas de coordenação das diferentes atividades realizadas pela firma. Trata-se de definir o ambiente interno da firma - por meio da divisão de trabalho - de coordenar a comunicação dessa especialização de tarefas e de definir a atribuição dos níveis de decisão (hierarquia) adotados na estrutura organizacional. Concomitantemente, a coordenação envolve a reconfiguração, ou transformação, da estrutura organizacional em função das alterações vislumbradas no ambiente da firma. Nesse contexto, a aprendizagem, reconhecida como um processo intrinsecamente social e coletivo, permite estabelecer os códigos comuns de comunicação e de reordenação das atividades em função da constante reavaliação do conhecimento adquirido. Na medida em que os processos organizacionais permitem a reavaliação das decisões adotadas na alocação de recursos (onde, quando, como, quanto investir), a avaliação dos resultados das decisões permite, como contrapartida, reavaliar e reconfigurar os processos gerenciais adotados. Esse processo retroativo de avaliação se configura também como um fenômeno de path-dependence, de forma que a coordenação dos recursos da firma irá determinar o escopo e os procedimentos de busca e seleção de informações consideradas relevantes. 
A partir da identificação desses elementos da análise, os autores propõem uma abordagem explicativa das estratégias de concorrência e de crescimento adotadas pelas empresas, baseando-se na forma como a posição, os caminhos e os processos interagem ao longo do tempo. Essa interação será discutida no quarto item deste artigo, quando da apresentação dos microfundamentos dessa abordagem.

\section{Os fundamentos de análise}

Teece, Pisano e Shuen $(1997,2002)$ atribuem a elaboração de seu referencial de análise sobre a capacidade dinâmica da firma aos fundamentos teóricos propostos, sobretudo por Schumpeter (1934), Penrose (1959), Williamson (1975), Teece (1980, 1982, 1986), Nelson e Winter (2005) e Wernerfelt (1984). A perspectiva comum de análise desses autores estaria baseada na especificidade dos recursos da firma como fator explicativo fundamental das vantagens competitivas obtidas diante dos seus concorrentes (resourcebase perspective). Contudo o próprio Wernerfelt (1984) reconhece o trabalho seminal de Edith Penrose, no seu livro Teoria do crescimento da firma, como a referência que deu origem à discussão da firma como um conjunto de recursos produtivos passíveis de serem recombinados pela estrutura organizacional, proporcionando uma visão alternativa à interpretação neoclássica da firma como um mero agente maximizador em um contexto de equilíbrio. Ao compartilharmos dessa visão, procuraremos a seguir identificar as principais contribuiçôes do trabalho de Penrose para a elaboração de uma teoria econômica da firma que dá ênfase não apenas à dimensão organizacional da firma, como também às suas possibilidades de mudança ao longo do tempo.

Ao tratar a organização como o locus da capacidade dinâmica da firma, outro referencial que nos parece fundamental é a abordagem evolucionária de Nelson e Winter (2005) no que tange ao seu caráter explicativo da diversidade empresarial identificado no nível das rotinas estabelecidas pela firma. Discutiremos, na seqüência, os principais aspectos teóricos dessa abordagem. 


\subsection{A firma como um conjunto de recursos}

Ao elaborar uma teoria compreensiva do crescimento da firma, Edith Penrose procurou mostrar que as causas e os limites desse fenômeno não estavam dados a priori por um comportamento maximizador que atenderia às condições de equilíbrio do mercado, mas sim pela capacidade da firma de alterar a sua estrutura administrativa, a fim de viabilizar a sua expansão (2006:53). Os limites neoclássicos do tamanho da firma, baseados na deseconomia de escala a partir de um determinado tamanho, definido pela demanda, seriam na realidade superados por novas formas de organização interna da produção, bem como pela possibilidade de diversificação de produtos. A firma não se limita à oferta de um produto único e homogêneo, mas se diversifica na medida em que identifica os limites físicos de expansão dos mercados em que atua.

Para Penrose (2006) a firma é mais do que uma unidade autônoma de decisão. A firma constitui-se como um conjunto de recursos produtivos, cuja recombinação permite estabelecer as condições de crescimento. Os recursos tangíveis ou intangíveis não são, contudo, o essencial numa firma, mas sim os serviços que esses recursos podem render. Os recursos constituem na realidade um conjunto de serviços potenciais, tendo, portanto, um caráter muitas vezes genérico, enquanto os serviços possuem um caráter específico voltados a atender determinada atividade ou função. E o que distingue uma empresa das demais é justamente a possibilidade que os mesmos recursos sejam usados, ou recombinados, de maneiras diferentes e com propósitos diversos (2006:131). Se pode haver uma série de recursos ociosos passíveis de serem aproveitados pela firma, o mais importante é o fato de que os recursos produtivos podem render diferentes serviços até então inusitados, com um custo muito reduzido, na medida em que eles estão disponíveis para a empresa.

As atividades produtivas que uma firma exerce, bem como a recombinação de recursos que ela possa vir a fazer, dependem das "oportunidades produtivas" vislumbradas pelos dirigentes da firma. A possibilidade de identificar tais oportunidades depende por sua vez dos recursos e serviços (de busca) disponibilizados pela firma. Isso significa que os limites de crescimento da firma são dados pelos limites da identificação das oportunidades produtivas, e não pelo pressuposto da existência de retornos decrescentes a partir de certo 
ponto de equilíbrio. Dessa forma, os recursos "herdados" pela firma num momento anterior irão definir os horizontes de observação do ambiente na qual ela se insere e a imagem que o empresário vislumbra em termos de oportunidades a serem exploradas (2006:72):

"[...] as 'expectativas' de uma firma - a maneira como ela interpreta seu 'entorno' - são tanto função dos recursos internos e das atividades de uma firma como das qualidades pessoais de seus empresários". (2006:85)

Em analogia com a abordagem da "capacidade dinâmica", percebe-se aqui que os sucessivos (re)posicionamentos da empresa ao longo do tempo se constituem em caminhos de dependência nos quais as decisões adotadas no presente são influenciadas por atitudes passadas. $\mathrm{E}$ as decisões atuais envolvem um grau considerável de subjetividade da parte do empresário naquilo que a autora considera uma predisposição psicológica para assumir riscos, ou seja,

"[...] a decisão de procurar as oportunidades é uma decisão empresarial que requer uma intuição e uma imaginação empreendedora, e que deve preceder a decisão 'econômica' de levar avante o exame das oportunidades de expansão". (2006:75)

A criação de uma "imagem" do ambiente da firma, eminentemente subjetiva, elaborada pelo empresário remete não apenas a sua predisposição psicológica ao risco e à obtenção de lucro, como também ao reconhecimento de que a demanda “[...] pode ser influenciada pelas suas próprias açôes” (2006:137). Nesse caso, o poder de intervenção das empresas é reconhecido como um dos fatores capazes de moldar o mercado a partir do que seria uma representação das idéias propostas pelos empresários. Assim, o caráter subjetivo das decisões é para Penrose um aspecto fundamental para a compreensão do crescimento da firma.

"Embora as oportunidades produtivas objetivas de uma firma sejam limitadas pelo que a firma é capaz de realizar, a oportunidade produtiva 'subjetiva' gira em torno do que ela pensa poder realizar." (2006:85) 
Cabe ressaltar que, para Penrose, tal subjetividade não é desprovida de racionalidade. O que ocorre é um misto de elementos objetivos e subjetivos na elaboração da imagem do ambiente da firma, concebida pelo empresário. Fato este que se torna o desafio teórico e empírico do economista na busca de compreender os mecanismos de interação da firma com seu ambiente.

"Dentro dos incognosciveis limites estabelecidos pelo entorno às atividades bemsucedidas, há amplo espaço para a emissão de julgamentos. Estaremos interessados no entorno 'imaginado' pelo empresário, pois queremos, acima de tudo, descobrir, entre outras coisas, que consideraçôes econômicas, em contraposição às temperamentais, determinam os juizos dos empresários sobre o entorno de suas firmas." (2006:86)

A discussão sobre a subjetividade da ação empresarial será objeto de análise dos microfundamentos da "capacidade dinâmica” da firma na próxima seção.

\subsection{Capacidades versus rotinas}

Segundo Brian Loasby (2002) o termo "capacidade" foi introduzido na literatura econômica no artigo "The organisation of industry" de Richardson (1972), no qual ele discute como a divisão de trabalho na indústria provoca o surgimento de diferentes organizações com capacidades específicas para desempenhar diferentes atividades produtivas. Seguindo a contribuição do trabalho de Penrose, Richardson observa que as organizaçóes tendem a especializar-se em atividades nas quais suas capacidades proporcionam vantagens competitivas. O autor reconhece que o termo "capacidade" é um tanto vago - sendo associado a conhecimento, experiência e habilidades -, constituindo-se, porém, numa fonte importante na diferenciação da atividade empresarial (Richardson, 1972:888).

Para Loasby (2002:49) a clarificação do termo "capacidade", usado como um conceito, está ligado ao potencial e aos limites de cognição humana, cuja implicação no âmbito da ciência econômica remete ao problema fundamental de tomada de decisão dos agentes em condição de racionalidade limitada. A ignorância parcial dos agentes adquire um caráter ontológico na 
medida da impossibilidade de lidar com uma infinidade de dados e de relacionálos em toda a sua complexidade (Loasby, 1976:2). Diante de um ambiente complexo, no qual o conhecimento é limitado, cabe aos agentes simplificar a realidade por meio de mecanismos que auxiliem na tomada de decisão. Isso implica criar mecanismos de busca mais ou menos simplificados, capazes de gerar indicadores confiáveis que representem aquilo que os agentes, ou empresas, esperam encontrar no ambiente.

Para Nelson e Winter (2005) tal capacidade está associada às rotinas, ou procedimentos organizacionais, que as empresas adotam, a fim de organizar seu repertório de atividades e de processamento de informações. As rotinas são consideradas por esses autores como a principal fonte de diversidade empresarial, na medida em que as soluções organizacionais desenvolvidas pelas empresas dependem fundamentalmente da experiência específica de cada uma na busca e no processamento das informações. E, uma vez que a dinâmica econômica, na perspectiva evolucionária, é guiada por fluxos de informaçôes (2005:517), o conceito de rotina deriva diretamente das dificuldades relacionadas à assimetria de informações. No entanto, essa abordagem não se limita a tratar a firma como uma resposta institucional à existência de assimetria de informações (Alchian \& Demsetz, 1972), sob condições de racionalidade limitada (Williamson, 1987; Simon, 1959). Na realidade, a firma, para Nelson e Winter (2005), constitui-se num repositório de conhecimento. o qual se expressa por meio das rotinas.

Como observa Winter, ${ }^{3}$ citado por Fransman (1998:171), a firma é definida como

"[...] organizations that know how to do things. Firms are repositories of productive knowledge. In fact [...] a particular firm at a particular time is a repository for a quite specific range of productive knowledge, a range that often involves idiosyncratic features that distinguish it even from superficially similar firms in the same line(s) of business". (Fransman, 1998:175)

3 Winter, S., "On Coase, competence and the corporation", Journal of Law, Economics and Organization, v.4, n.1, p.163-180, spring, 1988. 
Para compreender a função que as rotinas cumprem no funcionamento das organizaçooes, Nelson e Winter (2005) estabelecem uma analogia entre as habilidades individuais e as rotinas, ao considerarem os indivíduos "organizações complexas". A habilidade individual é assim reconhecida como a "[...] capacidade de ter uma seqüência regular de comportamento coordenado que em geral é eficiente em relação a seus objetivos" (2005:116). Para tanto, as habilidades envolvem três características fundamentais. São programáticas, dado que se constituem em comportamentos seqüenciais e automáticos, "[...] no sentido de que a maioria dos detalhes é executada inconscientemente" (2005:120). Esse automatismo pressupõe a existência de um conhecimento tácito, uma vez que o indivíduo não é capaz de elaborar verbalmente, ou conscientemente, os detalhes de suas atividades. E essas atividades envolvem, por sua vez, uma série de escolhas, cujas opções "[...] são selecionadas automaticamente e sem a consciência de que se está fazendo uma escolha" (2005:117). ${ }^{4}$

A partir dessas inferências, os autores extrapolam o padrão repetitivo das habilidades individuais ao desempenho organizacional estabelecido pelas rotinas. Assim, o procedimento repetitivo das rotinas permite, por um lado, acumular conhecimentos e experiência na tomada de decisões, fazendo com que os erros e acertos sejam processados na memória organizacional da firma. Por outro, a repetição continuada dos procedimentos rotineiros da firma engendra o risco de uma excessiva estabilidade desses procedimentos, o que limitaria as possibilidades de mudança da organização sob uma ótica inovadora. Mas, como observa Loasby (2002:30), em uma perspectiva evolucionista, a estabilidade é uma condição para a existência da mudança, fazendo com que certas rotinas - especialmente as de busca - tenham um caráter ambíguo, pois é na repetição dos procedimentos de tomada de decisão e de execução de tarefas que as mudanças ocorrem.

4 Os autores reconhecem aqui a influência da filosofia de Michael Polanyi na importância atribuída ao conhecimento tácito, a partir da sua observação de que "sabemos mais do que podemos dizer" (Polanyi, 1967:4). As fontes dos limites de articulação do conhecimento seriam nesse caso de três tipos: a comunicação simbólica que limita a velocidade de transmissão da informação; a falta de compreensão teórica, e portanto de análise e codificação, da habilidade utilizada; e o caráter linear da comunicação baseada na linguagem que impede a articulação coerente das partes ou seqüências para descrever o todo (Nelson \& Winter, 2005:127-128). 
Para Dosi, Nelson e Winter (2002:2), a “capacidade” está associada a uma ação intencional. A "capacidade" é o que está entre a intenção e o resultado. Já as rotinas envolvem muitas vezes um conhecimento tácito no qual a intenção não está explicitamente determinada, fazendo com que os processos produtivos e gerenciais não estejam bem compreendidos, o que pode limitar a capacidade de ação da firma. Por outro lado, algumas rotinas têm um caráter intencional, especialmente aquelas ligadas à coordenação das atividades intra e inter-firmas, confundindo-se, portanto, com as capacidades da firma.

$\mathrm{Na}$ medida em que a intencionalidade está associada às expectativas dos agentes, o grande desafio para o economista é como avaliar os critérios de julgamento dos empresários, sempre considerando que as decisões são tomadas a partir de elementos objetivos, por meio de procedimentos de busca e coleta de informações, e subjetivos. Surge daí uma série de questôes pertinentes à discussão sobre o processo de tomada de decisão: Como a agenda de decisões da firma é definida? Quais são os recursos que a firma mobiliza para atender sua agenda? Como o empresário elabora a imagem do ambiente da firma? Qual é o grau de objetividade ou subjetividade dessa imagem? Quais são os procedimentos de busca que a firma utiliza para ter acesso a informações? Quais são os mecanismos de coordenação da divisão do trabalho intra e inter-firmas de que a empresa se utiliza? Quais são os procedimentos de reflexão e de aprendizagem que a empresa adota para avaliar suas decisões? Por último, qual é o grau de objetividade do próprio economista, ao observar seu objeto de estudo?

\section{Os microfundamentos de análise}

A capacidade dinâmica da firma, ou seja, a capacidade de recombinar os recursos da firma em função das mudanças de seu ambiente, remete a dois problemas econômicos fundamentais com que os agentes (empresários) se defrontam: a interpretação do entorno da firma e a coordenação dos recursos inter e intra-firma. Tanto a interpretação quanto a coordenação são atividades intrinsecamente relacionais que dependem da interação com outros indivíduos, em um contexto coletivo. Defrontamo-nos nesse caso com o problema clássico da relação agência - estrutura, na qual se discute como os indivíduos 
configuram e são configurados pelo seu contexto social. Esse nível de discussão remete a um esforço de compreensão dos microfundamentos das formas como o indivíduo percebe e interage com outros indivíduos, chegando no nível psicológico de análise do homo economicus.

\subsection{Do cognitivo}

Em uma perspectiva de racionalidade limitada dos agentes, a decisão é uma conseqüência da escassez e da imperfeição das informações, pois, se o conhecimento fosse completo, não haveria escolha, mas um mero ato reflexo de estímulo-resposta (Loasby, 1976:5). Nesse caso, o comportamento maximizador dos agentes, baseado no conhecimento completo, descartaria a possibilidade de ação sobre o ambiente, tornando-os meros sujeitos passivos em um modelo socioeconômico determinado.

$\mathrm{Na}$ perspectiva evolucionista o indivíduo tem a qualidade de ajustar seu comportamento em função das informações que ele recebe, ou percebe, do ambiente. $\mathrm{O}$ indivíduo é assim considerado portador de funções cognitivas que, por meio de esquemas mentais operados por um mecanismo de feedback, permitem assimilar e reinterpretar as informações percebidas (Rizzello, 1997:106). Na abordagem cognitivista toda percepção sensorial é necessariamente "abstrata", devendo, portanto, ser considerada uma interpretação de um evento a partir da experiência passada do indivíduo. A assimilação da informação, no sentido de tornar símile, corresponde a um processo de classificação das propriedades do ambiente percebidas por meio da associação de similaridade com as informações já adquiridas. Assim, novas informações desencadeiam reações no esquema cognitivo de forma que o indivíduo avalie a relevância dessas informações, podendo descartá-las, incorporá-las por similaridade às experiências passadas ou ainda reajustar seus esquemas mentais (Hayek, 1976). ${ }^{5}$

Como observa Loasby (2002:41), as escolhas, as decisões, ${ }^{6}$ são feitas por meio de conexões. E, como o indivíduo é um ser social, a confiança na suas

\footnotetext{
5 Esse trabalho de Hayek (The sensory order) foi escrito na década de 1920, mas só publicado em 1952.

6 Decidir significa cortar (de-caedere), ou seja, estabelecer de uma vez por todas o sentido das coisas (Galimberti, 2006:43).
} 
decisões depende da aprovação ou do julgamento de outros. Isso remete a uma dimensão coletiva do desenvolvimento cognitivo do indivíduo, na qual a percepção e a interpretação das informações relevantes dependem de um aparato de classificação coletiva, ou seja, de instituições. Isso remete à discussão acerca da intersubjetividade do processo de tomada de decisóes dos agentes.

\subsection{Do subjetivo ao intersubjetivo}

Considerando-se que as ações dos indivíduos seguem esquemas cognitivos que não são percebidos pela consciência, as suas decisões pertencem ao plano do subjetivo, no sentido de que se originam de sujeitos perceptivos, diferente do plano "objetivo" - associado ao universo dos objetos percebidos. E, na medida em que os sujeitos interagem por meio de regras e de códigos de comunicação comuns (instituições), as suas açōes, decisões e interpretações adquirem um caráter interpessoal, intersubjetivo (Hayek, 1976:23).

$\mathrm{Na}$ linha cognitivista de Hayek, Boulding $(1961)^{7}$ propõe uma teoria do conhecimento baseado na subjetividade da imagem que se estabelece na mente do indivíduo e que ao mesmo tempo é compartilhada pela sociedade. Ao considerar a "imagem" como um conhecimento subjetivo, a questão central de seu trabalho é de compreender como a "imagem" é determinada. Para Boulding, as informaçóes correspondem a mensagens recebidas pelo cérebro, as quais podem corroborar, alterar parcialmente ou romper totalmente a imagem previamente formada. As imagens seriam classificadas como imagens de "fato" ou de "valor", ressaltando que as mensagens que constroem os fatos em nosso cérebro são filtradas por um sistema mutável de valores.

A imagem é também para Boulding uma construção coletiva, na qual os indivíduos participam por meio de organizaçôes, definidas como "[...] structure of roles tied together with lines of communication [...]", na qual a unidade básica não é o indivíduo, mas parte de indivíduos que exercem determinado papel. Por esse motivo, cada indivíduo é capaz de participar de várias instituiçôes atuando em diferentes papéis (Boulding, 1961:27). Em outras palavras, o que importa não são os indivíduos mas as relações entre eles. No caso

\footnotetext{
7 Esse trabalho de Kenneth Boulding foi inicialmente publicado em 1956.
} 
das organizações, o que está em jogo é a especialização das tarefas, a qual se estabelece por meio da divisão do trabalho. Isso nos remete ao problema de coordenação dessa divisão no sentido de que as mensagens que circulam na organização possam ser compartilhadas e tenham, ao menos em parte, uma imagem (sentido) comum. Isso pressupóe que a subjetividade de cada indivíduo seja compreendida por outros que compartilham a mesma realidade, no sentido de serem capazes de estabelecer uma imagem mais ou menos homogênea de seu ambiente.

\subsubsection{Intersubjetividade inter e intra-firma}

Surge daí o primeiro problema de interação entre os sistemas de percepção (individuais) e as redes de relações (coletivas). Essa interação se estabelece tanto no nível do ambiente externo da firma quanto no nível interno. No nível externo, a firma deve ser capaz de compartilhar informaçôes com seus clientes e fornecedores de forma a reduzir a assimetria destas a um nível que viabilize os custos de transação. Ao mesmo tempo, ela deve ser capaz de identificar a sua posição no mercado vis-à-vis seus concorrentes, por meio de indicadores minimamente confiáveis, que permitam a redefinição das suas possibilidades de ação com vista a manter ou ocupar posições mais vantajosas. Essa redefinição das possibilidades de ação está limitada por uma percepção transitória dos fenômenos de causalidade que o empresário é capaz de observar. E essa percepção transitória dos fenômenos se expressa na forma como eles são assimilados, conhecidos, reconhecidos e compartilhados pela memória individual do empresário vis-à-vis a memória coletiva da firma - as rotinas. Tais procedimentos dependem da coordenação das atividades no interior da firma: das rotinas de busca e de avaliação, da troca de informações entre as diferentes atividades, da recombinação dos recursos produtivos.

O seu desempenho, ou competitividade, dependerá por sua vez da sua capacidade de inserção na organização no nível da indústria, ou seja, da sua capacidade de combinação com os atores que compóem o entorno da firma: clientes, fornecedores, agentes reguladores, entidades de classe, agentes reguladores etc. (Richardson, 1972). Na medida em que a firma, o empresário, usa a sua experiência, ele resgata a sua memória de forma dinâmica, ao reavaliar, 
re-significar suas ações, num constante reformular do passado (Tacussel, 1998). Nesse caso, a temporalidade histórica será tanto mais importante na partilha intersubjetiva do sentido (intra e inter-firma) quanto maior for o dinamismo da indústria na qual a firma se insere. Nesse caso, as diferentes percepções dos agentes, ou das empresas, estão condicionadas pelo acúmulo de experiências de cada um, e também pela especificidade do momento histórico na qual cada experiência se deu. Essa temporalidade das experiências faz com que a troca destas se expresse por meio de uma intersubjetividade que é essencialmente histórica e provisória, posto que muda ao longo do tempo.

É assim que, no nível interno da firma, diferentes organizaçôes desenvolvem capacidades específicas em função das posições e dos caminhos que percorrem. A re-combinação dos recursos envolve a adoção de estratégias, táticas ou técnicas gerenciais (alocação, convencimento, imposição) que possibilitam a utilização mais eficaz dos recursos disponíveis. A técnica gerencial mais eficaz será aquela que possibilite distribuir sentido para os indivíduos (intersubjetividade), de forma a reduzir os custos de convencimento e de adesão a um projeto coletivo que transcenda, ao menos em parte, os interesses individuais. Ao mesmo tempo, será aquela capaz de simplificar a realidade essencialmente complexa, a fim de possibilitar a tomada de decisões a um custo mais baixo possível.

Como observa Loasby (1976:81): "One obvious way in which a firm may, over time, reduce decision costs without impairing the quality of decisions is by organising its experience". A organização dessa experiência passa em geral por um processo administrativo, ou um ciclo clássico de decisão (inteligência, busca, escolha, implementação, avaliação) capaz de simplificar artificialmente a complexidade do ambiente da empresa por meio da elaboração de problemas que levam a soluçôes satisfatórias (1976:89). O início do ciclo pela "inteligência" significa que a firma, ao coletar fatos relevantes do ambiente, pode desencadear um processo de avaliação e de escolha de possíveis caminhos a seguir, no qual "[...] the declaration of a particular state of the world leads to the selection of the appropriate set of actions" (1976:90). Por outro lado, a coleta dos fatos significa a existência de um modelo pré-concebido da realidade em função, ou seja, de uma organização prévia da experiência adquirida. 
Loasby (1976) identifica a existência de quatro padrões básicos de tomada de decisões da firma: esta pode guiar-se exclusivamente pela sua experiência prévia (historical standards); por referências externas de outras empresas, concorrentes ou não (external standards); pelo planejamento de ações futuras, fundamentado em objetivos e metas específicas (planning standards); ou pela elaboração de hipóteses ou conjecturas de cenários prováveis e desejáveis para a firma (imaginative standards). Nesse último caso a firma tende a seguir o caminho contrário ao esforço gerencial de redução de incertezas. Contudo, é a criação de incertezas que proporciona as maiores oportunidades à firma (1976:103). Pode-se nesses casos inferir que a capacidade dinâmica de uma firma passaria pela combinação desses diferentes padrões de ação, considerando que os dois últimos (planejamento e imaginação) sejam os ingredientes mais significativos para definir o dinamismo de uma organização.

Se esses padrões permitem estabelecer uma rotina de tomada de decisões mais ou menos confiável, de forma a reduzir os custos da sua implementação e os riscos das suas conseqüências, as decisões mais críticas ocorrerão, no entanto, nas situações inesperadas. Naquelas situaçōes que escapam justamente do escopo do processo rotineiro adotado, podem existir duas situaçôes: ou a firma incorpora a experiência inusitada em suas rotinas de ação; ou simplesmente abandona essa experiência limitando-se a uma mera solução ad hoc de um determinado problema que se apresenta, sem que haja qualquer repercussão em termos da imagem e das intenções previamente estabelecidas pela firma (Winter, 2002).

Podemos tirar dessa discussão algumas questóes relevantes que podem guiar o economista na análise da capacidade dinâmica da firma: Quais são as estratégias de combinação que a empresa adota com os demais atores da indústria? Como a firma organiza a sua experiência? Qual é a sua capacidade de identificar a posição na qual ela se situa? Qual é a sua capacidade de refletir sobre as trajetórias adotadas? E qual é a sua capacidade de refletir sobre as futuras trajetórias?

\subsubsection{Intersubjetividade sujeito-objeto}

Hayek (1937), em seu artigo "Economics and knowledge", procura discutir como as suposições e proposições sobre o conhecimento que os diferentes 
membros da sociedade possuem influenciam na análise econômica. Mais especificamente Hayek se coloca a questão de até que ponto a análise econômica formal leva a algum conhecimento sobre o que ocorre no mundo real. A partir daí ele procura mostrar a insuficiência metodológica da teoria neoclássica na explicação de como o conhecimento é adquirido e comunicado. A sua crítica parte da constatação de que o conteúdo empírico dessa teoria consiste de proposições sobre a aquisição do conhecimento do indivíduo isolado de seu contexto social. E, se os agentes não são considerados estritamente oniscientes, eles são ao menos tidos como conhecedores automáticos das informações relevantes (1937:9). Essa arbitrariedade do economista, enquanto observador de uma realidade, nada mais é do que a subjetividade inerente ao sujeito da pesquisa (pesquisador), que, nesse caso, procura adaptar a interpretação da imagem de seu objeto ao pressuposto axiomático da existência de equilíbrio. Nesse caso, "[...] a afirmação de que, se as pessoas sabem tudo, elas estão em equilíbrio é verdade simplesmente porque é como se define o equilíbrio [...]" (1937:10). Essa tautologia, baseada na subjetividade do observador, impede justamente que se estabeleça uma comunicação intersubjetiva entre o sujeito (pesquisador) e o objeto (agente), sem contar que a própria intersubjetividade dos agentes é negligenciada, na medida em que o seu entorno social não é levado em consideração.

Para Hayek a forma de superar essa tautologia seria a de estabelecer um pressuposto teórico, não como um axioma, mas como uma conjectura a ser testada empiricamente, tal como fazem os agentes econômicos ao testarem as decisões adotadas (Loasby, 2002).

$\mathrm{Na}$ medida em que a abordagem evolucionista critica justamente o caráter axiomático da teoria neoclássica - e, portanto, pouco aderente à realidade -, deve-se ter o cuidado de refletir sobre o caráter intersubjetivo das relaçóes que se estabelecem entre o economista e o seu objeto de estudo. Uma vez que tal objeto corresponde a uma organização de indivíduos, cujo acesso a esta se dá em grande parte por meio de entrevistas de determinados indivíduos, a intersubjetividade daí decorrente se estabelece ao menos em dois aspectos que consideramos relevantes. O primeiro é de considerar o indivíduo entrevistado como o porta-voz de uma coletividade. Por mais que esse indivíduo possa representar e expressar a intencionalidade de uma empresa, 
é evidente que a imagem por ele fornecida não será mais do que uma visão parcial, em função dos seus próprios limites de conhecimento. Uma forma de reduzir essa limitação é obviamente a interlocução com várias pessoas, de diferentes departamentos da empresa, de forma a perceber a homogeneidade e a heterogeneidade dessas imagens. Outro aspecto a ser observado é o confronto que se estabelece - no momento de uma pesquisa - entre o entrevistador e o entrevistado, entre o conhecimento previamente organizado pelo entrevistador (teoria) e o conhecimento previamente organizado pelo entrevistado (experiência).

A interação entre ambos pode levar, por um lado, a um processo de aprendizagem recíproco ou unilateral, por meio do qual o conhecimento previamente adquirido é passível de ser reavaliado. Nesse caso, a técnica de um questionário o menos estruturado possível poderia, em princípio, auxiliar na avaliação da capacidade do entrevistado (o empresário) de refletir sobre a imagem interna e externa da firma, de forma a minimizar a condução da entrevista. Mas, na medida em que a condução, em maior ou menor grau, é inevitável, deve-se levar em consideração que a influência recíproca nas imagens de ambos os interlocutores é inerente à intersubjetividade aí estabelecida. Na visão de Callon (1998), a ciência econômica, na realidade, mais influencia a economia - por meio de seus instrumentos de análise explicativa e normativa - do que é capaz de observar seu funcionamento. Tal afirmação se fundamenta no reconhecimento de uma ontologia do agente que, ao ser configurado pelas relações que estabelecem com outros agentes, determina a sua racionalidade, a sua capacidade de cálculo, de tomada de decisões. Essa capacidade é tanto mais influenciada quanto maior for a utilização prática do instrumental teórico proposto pelo economista, ou seja, quanto maior for a sua capacidade de testar e validar os instrumentos de análise propostos.

"We see why we have to be wary of the catch-all that socio-economics likes to use as a rallying cry: the market is socially constructed. What is under construction is precisely this heterogeneous collective, populated by calculating agencies. Society is not a starting point, a resource or a frame; it is, along with the market, the temporary outcome of a process in which social sciences economics in this case - are the stakeholder." (1998:30) 
Por outro lado, essa interação entre entrevistador e entrevistado pode levar a um processo de ratificação das conjecturas do pesquisador, no qual o auto-engano tende a inibir a sua capacidade crítica. $\mathrm{O}$ mais provável é que ambos os casos ocorram em diferentes graus de combinação, dependendo da capacidade de reflexão teórico-metodológica do pesquisador.

\section{Conclusão}

A capacidade dinâmica, em uma perspectiva evolucionária, pressupõe uma intencionalidade das ações da firma voltadas à manutenção da sua competitividade num ambiente marcado pela mudança. Essa capacidade se constitui na fonte da diversidade organizacional das empresas inseridas num ambiente de seleção. E a avaliação dessa capacidade passa, sobretudo, pela identificação das intenções da firma para atingir determinadas posições estratégicas, dos caminhos trilhados para atingir tais posiçôes e dos recursos mobilizados para tais finalidades.

A capacidade da firma de viabilizar o seu constante reposicionamento estratégico nos mercados nos quais atua envolve a análise de duas atividades econômicas fundamentais: o da percepção/interpretação do ambiente e o da coordenação dos recursos internos e externos. Tais atividades têm, por sua vez, a finalidade de subsidiar o processo de tomada de decisóes dos agentes. Uma vez que o conhecimento é reconhecido como um insumo escasso e impreciso, a racionalidade limitada dos agentes está impregnada de elementos subjetivos que compõem a imagem e as expectativas daquilo que eles acreditam poder realizar. A subjetividade não se limita ao indivíduo, outrossim, é compartilhada entre vários indivíduos que compõem o seu entorno social, por meio de mecanismos de troca de mercadorias, de informações etc. Dessa forma, a proposta de compreensão dos elementos cognitivos que compõem a mente do indivíduo segue no esforço de estabelecer uma ontologia do "homem econômico" baseada em proposições conjecturais que levem em consideração a racionalização intersubjetiva de suas ações. Tal racionalização passa por sua vez pela intersubjetividade disciplinar, pelo pluralismo das ciências que se propõem a compreender as interações desse "homem econômico" vis$\grave{a}$-vis as mudanças de seu entorno. O desafio metodológico dessa compreensão 
passa, portanto, por uma intersubjetividade disciplinar (economia, filosofia, psicologia, sociologia) que permita estabelecer categorias ontológicas capazes de favorecer a comunicação não apenas entre as ciências, mas também entre o sujeito da pesquisa e o seu objeto.

\section{Referências bibliográficas}

Alchian, A.; Demsetz, H. "Production, information costs, and economic organization", American Economic Review, v.62, p.777-795, 1972.

Boulding, K. The image, Michigan: Ann Arbor, 1961.

Callon, M. "Introduction: the embeddedness of economic markets in economics", in Callon, M. (ed.), The laws of the markets, Oxford: Blackwell Publishers, p.1-57, 1998.

Chandler, A. Strategy and structure, Cambridge: MIT Press, 1962.

Dosi, G.; Nelson, R.; Winter, S. "Introduction: the nature and dynamics of organizational capabilities", in The nature and dynamics of organizational capabilities, Oxford: Oxford UP, p.1-22, 2002.

Fransman, M. "Information, knowledge, vision and theories of the firm", in Dosi, G.; Teece, D.; Chytry, J. (eds.), Technology, organization and competitiveness: perspectives on industrial and corporate change, Oxford: Oxford UP, p.147-191, 1998.

Galimberti, U. Psique e tecnhe: o homem na idade da técnica, São Paulo: Paulus, 2006.

Hayek, F. "Economics and knowledge", Economica, IV, p.33-54, 1937. The sensory order, Chicago: Chicago UP, 1976.

Henderson, B. "As origens da estratégia", in Prahalad, C. et al., Estratégia, São Paulo: Campus, p.3-9, 1998. 
Learned, E.; Christensen, C.; Andrews, K.; Gut, W. Business policy, text and cases, Homewood Illinois: Richard D. Irwin, 1965.

Loasby, B. Choice, complexity and ignorance, Cambridge: Cambridge UP, 1976. Knowledge, institutions and evolution in economics, Nova York: Routledge, 2002.

Montgomery, C.; Porter, M. "Introdução", in Prahalad, C. et al., Estratégia, São Paulo: Campus, p.XI-XXIII, 1998.

Nelson, R.; Winter, S. Uma teoria evolucionária da mudança econômica, Campinas: Editora da UNICAMP, 2005.

Nicolau, I. O conceito de estratégia, Lisboa: ISCTE, nov., 2001. Disponível em <http:// 213.13.125.90/portallizer/upload_ficheiros/01-01_Isabel_Nicolau.pdf $>$. Acesso em 19 de março de 2007.

Penrose, E. The theory of the growth of the firm, Londres: Blackwell, 1959. Teoria do crescimento da firma, Campinas: Editora da UNICAMP, 2006.

Polanyi, M. The tacit dimension, New Cork: Doubleday Anchor, 1967.

Richardson, G.B. "The organisation of industry", Economic Journal, v.82, p.883- 896, 1972.

Rizzello, S. "The microfoundations of path dependency", in Magnusson, L.; Ottosson, J. (orgs.), Evolutionary economics and path dependence, Cheltenham: Edward Elgar, 1997.

Schumpeter, J. The theory of economic development. Cambridge: Harvard UP, 1934.

Simon, H. "Theories of decision making in economics and behavioral science", American Economic Review, v.49, p.253-283, 1959.

Tacussel, P. "Comunidade e sociedade: a partilha intersubjetiva do sentido", Geraes Revista de Comunicação Social, n.49, p.3-12, 1998.

Teece, D. "Economics of scope and the scope of an enterprise", Journal of Economic Behaviour and Organization, n.1, p.223-247, 1980.

"Towards an economic theory of the multiproduct firm", Journal of Economic Behaviour and Organization, n.3, p.39-63, 1982. 
Teece, D. "Profiting from technological innovation", Research Policy, v.15, n.6, p.285305, 1986.

Teece, D.; Pisano, G. "The dynamic capabilities of firms: an introduction”, Industrial and Corporate Change, v.3, n.3, p.537-556, 1994.

Teece, D.; Pisano, G.; Shuen, A. "Dynamic capabilities and strategic management", Strategic Management Journal, v.18, n.7, p.509-533, 1997.

. "Dynamic capabilities and strategic management", in Dosi, G. et al., (orgs.), The nature and dynamics of organizational capabilities, Oxford: Oxford UP, p.334-362, 2002.

Wernerfelt, B. "A resource-based view of the firm", Strategic Management Journal, v.5, p.171-180, abr.-jun., 1984.

Williamson, O.E. Markets and hierarchies, Nova York: The Free Press, 1975. The economic institutions of capitalism, Nova York: The Free Press, 1987.

Winter, S. "Understanding dynamic capabilities", Working Paper, 2002-05, Reginald H. Jones Center, The Wharton School, University of Pensylvania, 2002.

ENDEREÇOS PARA CORRESPONDÊNCIA:

VictorPelaez-victor@ufpr.br

Av. Prefeito Lothário Meissner, 632, Andar Térreo, Jardim Botânico, Departamento de Economia - UFPR

Curitiba, PR 80210-170 / Tel: (41) 3360-4399

Marcelo Melo-marcelofmelo@gmail.com

Rua Professor Algacyr Munhoz Mader, 3775, Cidade Industrial de Curitiba, TECPAR

Curitiba, PR 81350-010

Ruth Hofmann-ruthofmann@gmail.com

Rua Professor Algacyr Munhoz Mader, 3775, Cidade Industrial de Curitiba, TECPAR

Curitiba, PR 81350-010 / Tel: (41) 3316-3053/ (41) 3316-3054

Dayani Aquino - dayani.aquino@gmail.com

Av. Prefeito Lothário Meissner, 632, Andar Térreo, Jardim Botânico, Departamento de Economia - UFPR

Curitiba, PR 80210-170 / Tel: (41) 3360-4350 